\title{
MONITORING OF CRITICAL PARAMETERS OF RADIATION STERILIZATION PROCESS AT AN INDUSTRIAL ELECTRON ACCELERATOR
}

\author{
R.I. Pomatsalyuk ${ }^{*}$, V.Yu. Titov, D.V. Titov, V.L. Uvarov, V.A. Shevchenko, A.A. Zakharchenko
}

National Science Center «Kharkov Institute of Physics and Technology» (NSC KIPT), Ukraine

\begin{abstract}
The use of ionizing radiation is a safe and effective method for sterilizing medical devices, pharmaceuticals and food products. In accordance with the requirements of international standards, a necessary condition of the process $Q A$ is to maintain its critical parameters within the specified limits. Primarily, such parameters are the electron energy and absorbed dose. The value of the latter must be controlled in each unit of the processed product. Traditionally, the disposable chemical dosimeters are used in an off-line mode for these purposes. For on-line monitoring of beam energy and absorbed dose, a method based on measurement of distribution of the charge induced by irradiation in an extended stack monitor positioned behind an irradiated object was developed and implemented. In the report, a brief overview of a control system designed on the basis of an EPICS package for continuous monitoring of the processing parameters at a LU-10 industrial electron linac of NSC KIPT with beam energy of 8$10 \mathrm{MeV}$ is presented. The operation principle of the system is described, as well as the procedure and results of calibration of electron beam energy and absorbed dose measuring channels.
\end{abstract}

Keywords: Industrial electron linac, control system, electron beam energy, absorbed dose, radiation sterilization

\section{INTRODUCTION}

The irradiation efficiency depends on the measurements and the assessment of the absorbed dose in the process of radiation treatment. This is done using dosimetry systems having a known level of accuracy. Dosimetry systems used in industrial radiation processing of materials should comply with international standards ISO/ASTM (Table 1) [1]. Determination of the absorbed dose using such dosimeters is usually carried out after the irradiation process in off-line mode.

Tracking such critical parameters as electron beam energy and the absorbed dose in the irradiated object during processing of the product is very important. The use of a extended stack monitor (SM) in the form of a set of ten aluminum plates located behind the irradiated object makes it possible to continuously monitor the absorbed dose in the object and track changes in the electron beam energy. This allows one to adjust the treatment parameters (beam current, conveyor speed and scanning width) in real-time.

A method based on measuring the distribution of charge induced by radiation in the stack monitor has been developed for continuous monitoring of critical parameters [2]. The use of this method requires calibration measurements with determination of the corresponding coefficients.
Table 1. Dosimetry systems parameters

\begin{tabular}{|l|c|c|c|}
\hline $\begin{array}{l}\text { Dosimeter } \\
\text { system }\end{array}$ & $\begin{array}{c}\text { Method of } \\
\text { analysis }\end{array}$ & $\begin{array}{c}\text { Dose } \\
\text { range } \\
{[G y]}\end{array}$ & $\begin{array}{c}\text { Nominal } \\
\text { precision } \\
\text { limits } \\
{[\%]}\end{array}$ \\
\hline $\begin{array}{l}\text { Ceric-cerous } \\
\text { sulphate }\end{array}$ & $\begin{array}{c}\text { UV spectro- } \\
\text { photometry }\end{array}$ & $10^{3}-10^{6}$ & 3 \\
\hline L-alanine & EPR & $1-10^{5}$ & 0.5 \\
\hline $\begin{array}{l}\text { Perspex } \\
\text { systems }\end{array}$ & $\begin{array}{c}\text { VIS spectro- } \\
\text { photometry }\end{array}$ & $10^{3}-5 \times 10^{4}$ & 4 \\
\hline B3 film & $\begin{array}{c}\text { VIS spectro- } \\
\text { photometry }\end{array}$ & $10^{3}-10^{5}$ & 3 \\
\hline Calorimetry & $\begin{array}{c}\text { Resistance/ } \\
\text { temperature }\end{array}$ & $1.5 \times 10^{3}-$ & 2 \\
\hline
\end{tabular}

This article provides a brief description of monitoring system of the radiation treatment parameters based on the Experimental Physics and Industrial Control System (EPICS) package [3]. The procedure and results of the calibration of the measuring channels using stack monitor in the range of electron beam energies 8-10 $\mathrm{MeV}$ are described.

*rompom@kipt.kharkov.ua 


\section{ACCELERATOR AND CONTROL SYSTEM}

\subsection{Electron Accelerator $L U-10$}

A LU-10 electron linac $(10 \mathrm{MeV}, 10 \mathrm{~kW})$ operating in NSC KIPT has been providing radiation sterilization of medical devices, row materials and products of pharmaceutical and food industry for many years. The machine has following parameters:

- current pulse duration $4 \mu \mathrm{s}$,

- pulse current $0.4-1 \mathrm{~A}$,

- pulse repetition rate $150-300 \mathrm{~Hz}$,

- electron energy 8-10 MeV.

The accelerator has a magnetic analyzer (MA) for measuring the energy spectrum of electrons and a magnetic beam scanner that allows the operator to set the width and offset of the irradiated zone (Fig. 1). Stack monitor, located behind an irradiated object, consists of ten aluminum plates $120 \times 75 \mathrm{~cm}^{2}$ in size and separated by an air gap of $5 \mathrm{~mm}$. Thickness of the first and the last plates is $5 \mathrm{~mm}$, the other plates are $2 \mathrm{~mm}$ thick.

\section{Electron Accelerator LU-10}

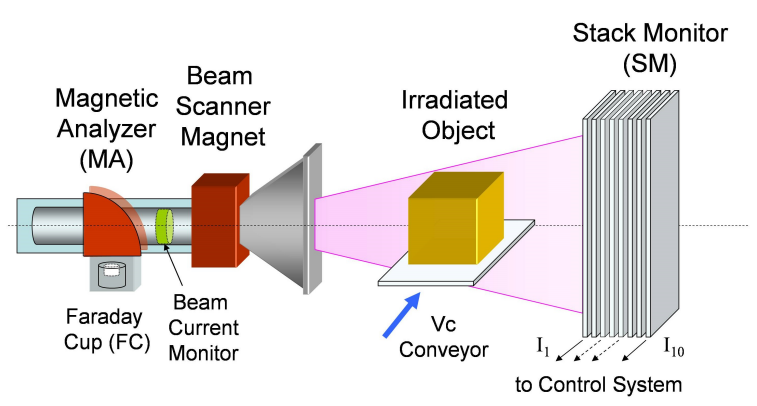

Figure 1. Diagram of LU-10 accelerator with irradiated object and stack monitor

\subsection{Control system of irradiation regime}

The control system of radiation processing parameters consists of the following elements (Fig. 2) [4]:

- database server (Linux OS);

- the local network;

- operator workstation with an "operator screens" (AWS);

- multifunctional data acquisition module type of NI USB-6341;

- measuring devices connected to the local network (oscilloscopes, multimeter, generator);

- EPICS input/output controllers (IOC).

The EPICS package was chosen as the software environment for the control system. The sweep signal for the scanner magnet is generated by the function generator type of SDG1010. The operation of the generator is controlled by an input/output controller via the USB bus. The controller IOC runs on a singleboard computer Raspberry Pi-3 with Linux system. The EPICS Archiver Appliance is used to store data of radiation processing parameters [5]. The control system uses more than 50 process variables (signals), which are recorded at regular intervals in the database. The annual data volume is about 2 GB. Data backup is carried out at regular intervals by copying the database files to external media: hard disk and flash memory (USB).

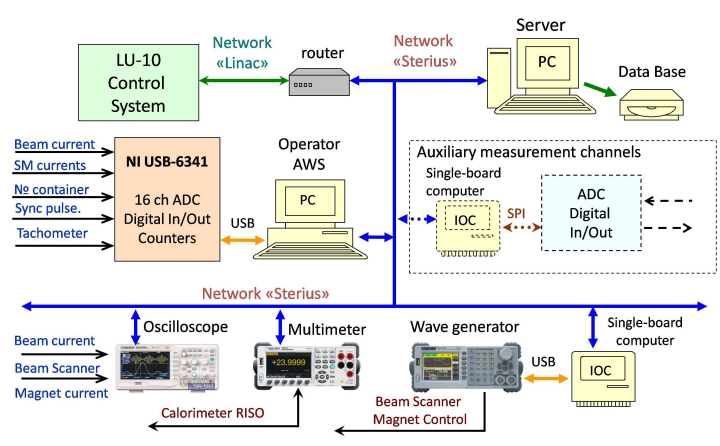

Figure 2. Block-diagram of control system

The parameters of the radiation process are displayed using graphical interfaces - "operator screens" (Fig. 3).

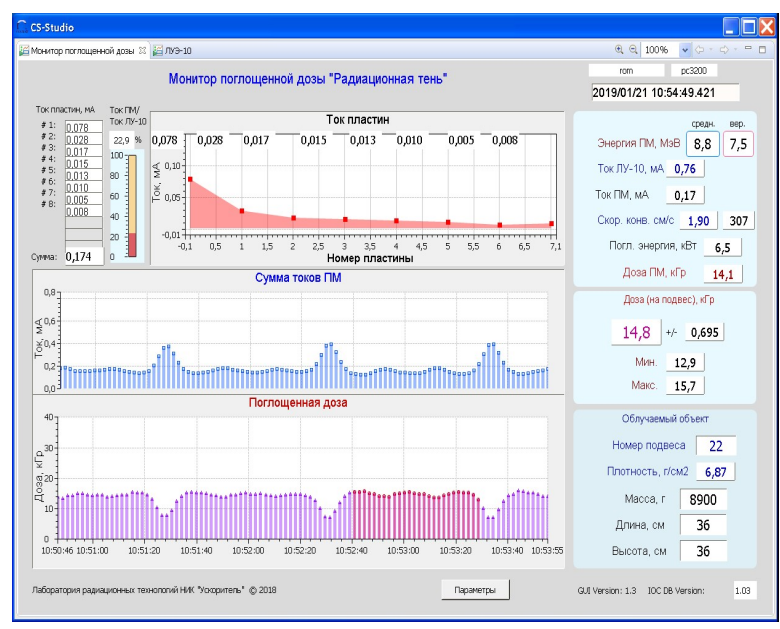

Figure 3. Operator screen "Monitor of energy and absorbed dose": top graph - current distribution from SM plates; bottom graph - time distribution of absorbed dose in irradiated object

\section{CALIBRATION OF MEASURING CHANNELS}

\subsection{Beam Energy calibration of stack monitor}

The procedure for calibrating the stack monitor for beam energy was as follows. Several measurements of energy spectra were carried out at average beam energy in the range from 8 to $10 \mathrm{MeV}$. The spectra were measured using a magnetic analyzer (MA) [6]. After each measurement of the spectrum, the current of each plate and the total current of the stack monitor without irradiated object were measured and recorded. The measured spectra were fitted with two Gaussians for accurate determination of the most probable and average energy of the electrons (Fig. 4). 


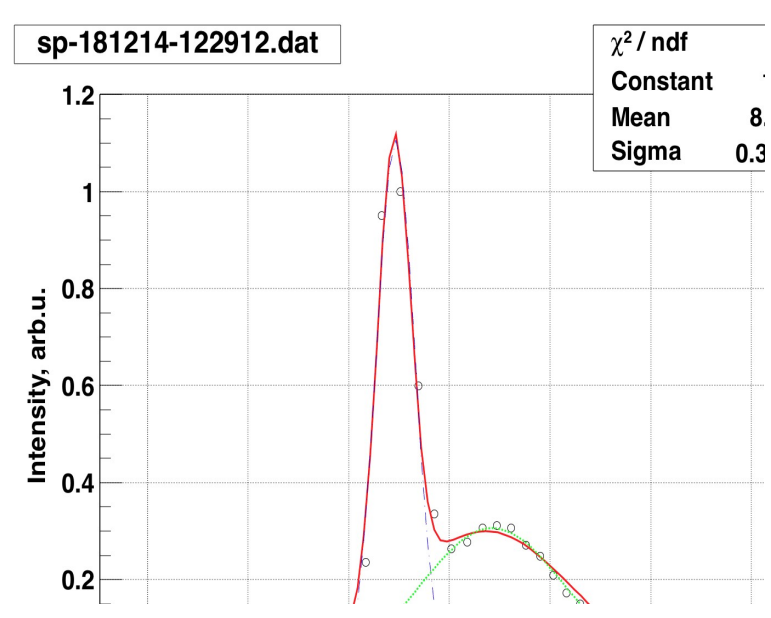

Figure 4. Measured spectrum with most probable energy

8.93 MeV and fitting with two Gaussians: circles measurement data using MA; solid line - combined fitting by two Gaussians

The following expression was used to determine the beam energy by the stack monitor:

$$
E=A+B \cdot \frac{\sum_{m}^{10} I_{i}}{I_{S M}},
$$

where $E$ - is the average electron beam energy $(\mathrm{MeV})$; $A, B$ - are the coefficients derived from the calibration measurements or calculations [2], $I_{i}-$ is the average current of $i$-plate of the stack monitor (A), $I_{S M}$ - is the average total current from all plates of the monitor (A).

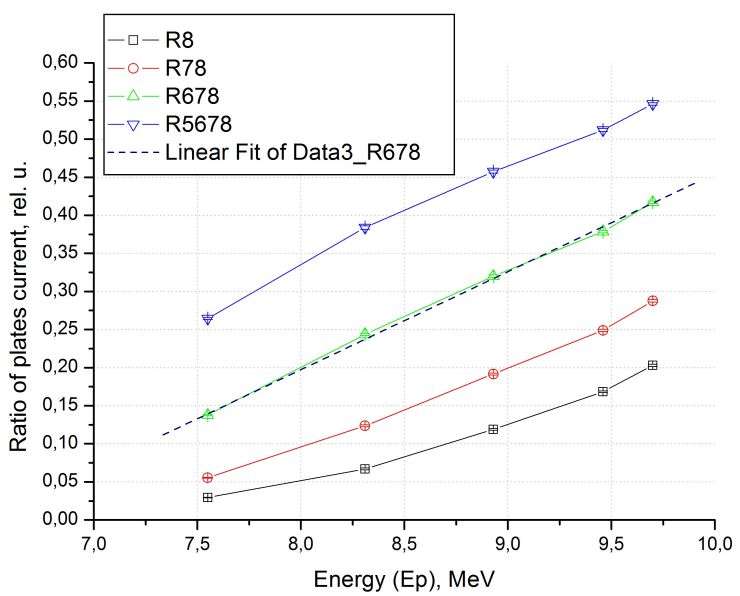

Figure 5 . Ratio of summary current of $k$ last plates to the total SM current versus most probable energy: $\mathrm{R} 8$ - $\mathrm{k}=(8,9,10)$; $\mathrm{R} 78$ - k=(7,8,9,10); R678 - k=(6,7,8,9,10); R5678 -

$\mathrm{k}=(5,6,7,8,9,10)$. Plate numbers are given in parentheses

The dependence of ratio of summary current $k$ last plates to the total current of SM on the most probable energy was obtained from the results of measuring the spectra and the distribution of currents from SM (Fig. 5). After approximating the selected distribution of R678, which has a straight line form, the following expression was obtained for calculating the most probable energy $(E p)$ :

$$
E_{p}=6.443+7.838 \cdot R
$$

where $\mathrm{R}$ - is the ratio of summary current of last 5 plates $(6,7,8,9,10)$ to the total SM current.

Also, the analytical dependence of average electron energy $(E a)$ on the ratio of sum of currents from plates $(6,7,8,9,10)$ to the total current SM was obtained:

$$
E_{a}=7.675+7.767 \cdot R
$$

The results of energy calibration by the stack monitor are presented in Table 2. The difference between energy measured by magnetic analyzer and energy measured by the stack monitor does not exceed $1 \%$.

Table 2. Results of beam energy measurement of LU-10 accelerator using magnetic analyzer MA and stack monitor SM

\begin{tabular}{|c|c|c|r|r|r|r|}
\hline $\mathrm{N}$ & $\begin{array}{c}\mathrm{MA} \\
E p, \\
\mathrm{MeV}\end{array}$ & $\begin{array}{c}\mathrm{SM} \\
E p, \\
\mathrm{MeV}\end{array}$ & $\begin{array}{c}\Delta E p \\
\%\end{array}$ & $\begin{array}{c}\mathrm{MA} \\
\mathrm{Ma}, \\
\mathrm{MeV}\end{array}$ & $\begin{array}{c}\mathrm{SM} \\
E a, \\
\mathrm{MeV}\end{array}$ & $\begin{array}{c}\Delta E a \\
\%\end{array}$ \\
\hline 1 & 9.46 & 9.41 & 0.52 & 11.05 & 11.0 & 0.50 \\
\hline 2 & 8.93 & 8.95 & -0.25 & 10.46 & 10.48 & -0.21 \\
\hline 3 & 8.31 & 8.35 & -0.51 & 9.75 & 9.81 & -0.63 \\
\hline 4 & 7.55 & 7.52 & 0.37 & 8.92 & 8.88 & 0.42 \\
\hline 5 & 9.70 & 9.71 & -0.12 & 11.32 & 11.33 & -0.09 \\
\hline
\end{tabular}

\subsection{Absorbed dose calibration}

The absorbed dose in an irradiated product depends on the average beam current, beam scan width, conveyor speed and beam energy. There is no simple relationship between dose and electron beam energy. Thus, the measurement of dose as a function of the three other parameters should be made for each operating energy [7].

The following materials and devices were used to calibrate the stack monitor by dose:

- dosimeters Red Perspex 4034 (RP),

- polystyrene calorimeter (RISO) (Fig. 6),

- foam polystyrene phantom F-1: dimension 79x41x37 $\mathrm{cm}^{3}$ (length, height, depth), weight $13 \mathrm{~kg}$, surface density $-3.96 \mathrm{~g} / \mathrm{cm}^{2}$;

- foam polystyrene phantom F-2: dimension $70 \times 38 \times 17.5 \mathrm{~cm}^{3}$, weight $-5.25 \mathrm{~kg}$, surface density $-2.0 \mathrm{~g} / \mathrm{cm}^{2}$ (Fig. 7).

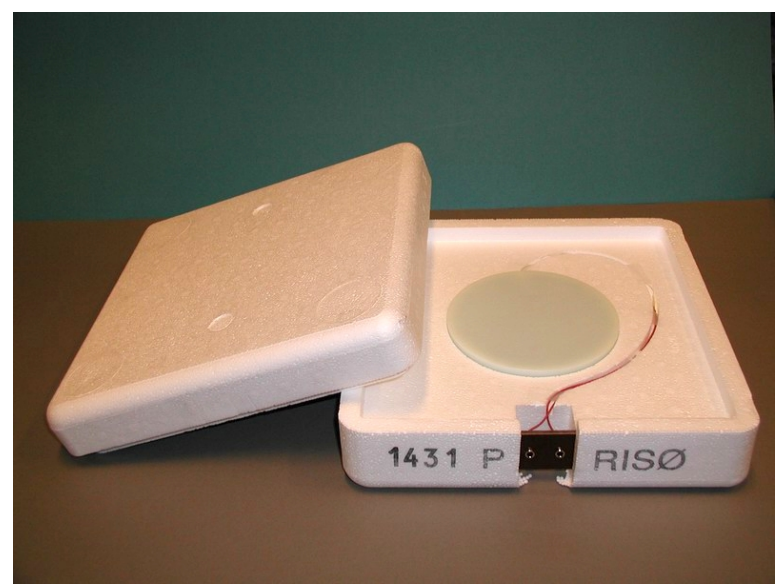

Figure 6. Polystyrene calorimeter RISO [8] 


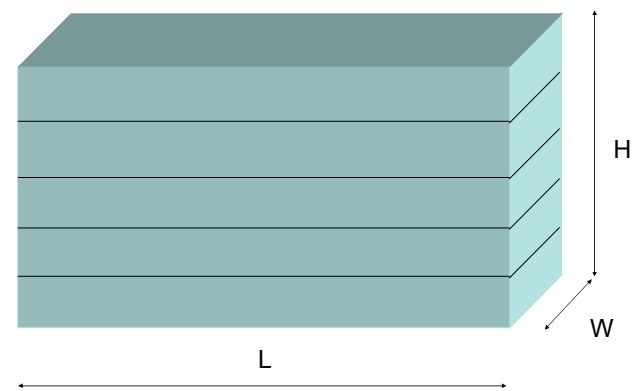

Figure 7. Foam polystyrene phantom F-1 and F-2

The RISO calorimeter consists of a polystyrene disk surrounded by heat-insulating foam (Fig. 6) [8]. The calorimeter temperature is measured by a calibrated thermistor, which is located inside the disk. The dose range is $3-40 \mathrm{kGy}$, the uncertainty of the dose measurements is $3.6 \%$.

The absorbed dose $D_{a b}(\mathrm{~Gy})$ in an irradiated object for the given energy and beam scanning width can be found from the equation [2]:

$$
D_{a b}=\left(a \cdot I_{b}-b \cdot I_{S M}\right) \cdot \frac{L}{V \cdot M}=P_{a b} \cdot \frac{L}{V \cdot M}
$$

where $I_{b}$ - is the average beam current of LU-10 (A), $I_{S M}$ - is the total current from all plates of the stack monitor (A), $V$ - is the conveyor speed $(\mathrm{m} / \mathrm{s}), m-$ is the irradiated object weight $(\mathrm{kg}), L-$ is the object length (m); $P_{a b}$ - is the absorbed power in the irradiated object (W); $a, b$ - are the calibration coefficients.

The coefficients $a, b$ are calculated from the expressions:

$$
a=b \frac{I_{S M}^{n}}{I_{b}^{c}}, b=\frac{P_{a b, p h}^{c}}{I_{S M}^{n}-I_{S M}^{c}},
$$

where $P_{a b, p h}$ - is the absorbed power in phantom, which can be found after calibration using expression:

$$
P_{a b, p h}^{c}=D^{c} \frac{V_{p h} \cdot M_{p h}}{L_{p h}}
$$

where $D_{c}$ - is the absorbed dose measured with dosimeters (RISO calorimeter or Red Perspex); $p h$ index denotes the phantom; $n$ - index denotes no irradiated object; $c$ - index denotes the calibration measurement.

The coefficients $a, b$ depend on the beam energy and beam scan width. Therefore, a set of coefficients is required for each value of energy and scan width to determine more accurately the absorbed dose using the stack monitor.

In the process of calibration, phantom $\mathrm{F}-1$ and RISO calorimeter moved at a given speed through the irradiation zone, and the beam current and the SM current were recorded (Fig. 8). The calibration measurements were carried out at various conveyor speed: $1.24 ; 2.48 ; 3.72 \mathrm{~cm} / \mathrm{sec}$; and at several values of average beam energy in the range $8-10 \mathrm{MeV}$.

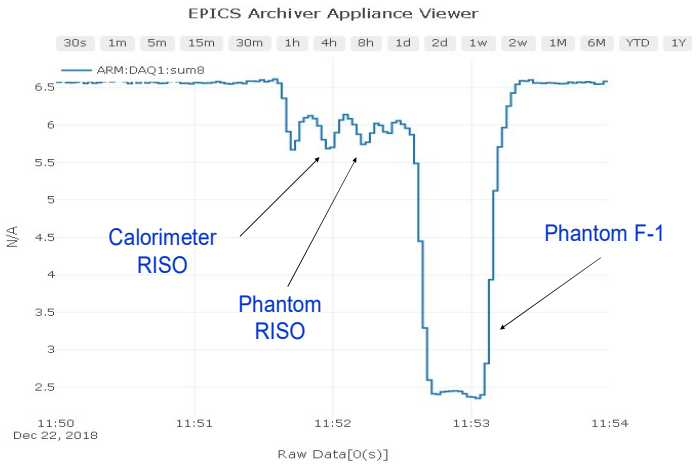

Figure 8. Total current (a.u.) of stack monitor during irradiating RISO calorimeter and phantom F-1

The absorbed dose was determined using the RISO calorimeter. Several measurements of the calorimeter temperature were performed before irradiation (T1) and then after irradiation (T2). The temperatures $T 1$ and $T_{2}$ were determined by the off-line method described in the standard ISO/ASTM51631:2020 [9]. The irradiation time $t_{i}$ was also recorded. The measured temperature values before and after irradiation are approximated by two straight lines (Fig. 9). The temperature $T 1$ and $T 2$ are determined by the value on the extrapolated line at the time of irradiation $t_{i}$.

The calculation of the absorbed dose $D$ in the RISO calorimeter was carried out using the expression:

$$
D=\left(T_{2}-T_{1}-T_{a}\right) \cdot\left(k_{1}+k_{2} \cdot \frac{T_{1}+T_{2}}{2}\right) \cdot k,
$$

where $T_{1}-$ is the calorimeter temperature before irradiation $\left({ }^{\circ} \mathrm{C}\right) ; T_{2}-$ is the calorimeter temperature after irradiation $\left({ }^{\circ} \mathrm{C}\right) ; T_{a}-$ is the calorimeter heating from conveyor and accelerator $T_{a} \sim 0,05^{\circ} \mathrm{C} ; k_{1}, k_{2}, k-$ are the calibration constants $\left(k_{1}=1,022 ; k_{2}=0,0108\right.$; $k=1,000$ ).

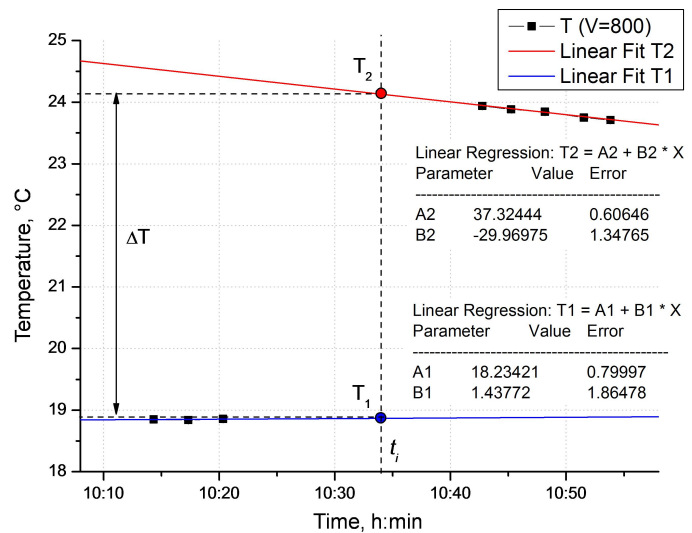

Figure 9. The temperature curves of the RISO calorimeter were extrapolated to $\mathrm{T} 1$ and $\mathrm{T} 2$ (the irradiation time at $t_{i}$ ). $\Delta \mathrm{T}=\mathrm{T} 2-\mathrm{T} 1$ is used for dose calculation.

The results of calculating the coefficients $a, b$ and the absorbed dose in the phantom F-1 measured using the SM at different beam energies are shown in Table 3 . 
Table 3. Results of dose calibration of stack monitor

\begin{tabular}{|c|c|c|c|c|c|c|c|c|}
\hline № & $\begin{array}{l}\text { Cur- } \\
\text { rent } \\
\mathrm{mA}\end{array}$ & $\begin{array}{c}\mathrm{Ep} \\
\mathrm{MeV}\end{array}$ & $\mathbf{a}$ & Coeff & cients & $\pm \Delta \mathbf{b}$ & $\begin{array}{c}\text { Dose } \\
\text { F-1 } \\
\text { RP, } \\
\text { kGy }\end{array}$ & $\begin{array}{c}\text { Dose } \\
\text { F-1 } \\
\text { SM, } \\
\text { kGy }\end{array}$ \\
\hline 1 & 0.77 & 9.13 & 10.1 & 0.26 & 12.5 & 0.29 & 8.48 & 8.32 \\
\hline 2 & 0.71 & 9.71 & 11.9 & 0.52 & 14.9 & 0.61 & 8.40 & 8.44 \\
\hline 3 & 0.45 & 10.71 & 15.6 & 0.51 & 17.5 & 0.55 & 6.15 & 5.61 \\
\hline 4 & 0.74 & 8.42 & 7.1 & 0.20 & 9.0 & 0.22 & 6.79 & 6.18 \\
\hline
\end{tabular}

The dependence graph of the coefficients $a, b$ on the most probable energy of the electron beam is shown in Fig. 10.

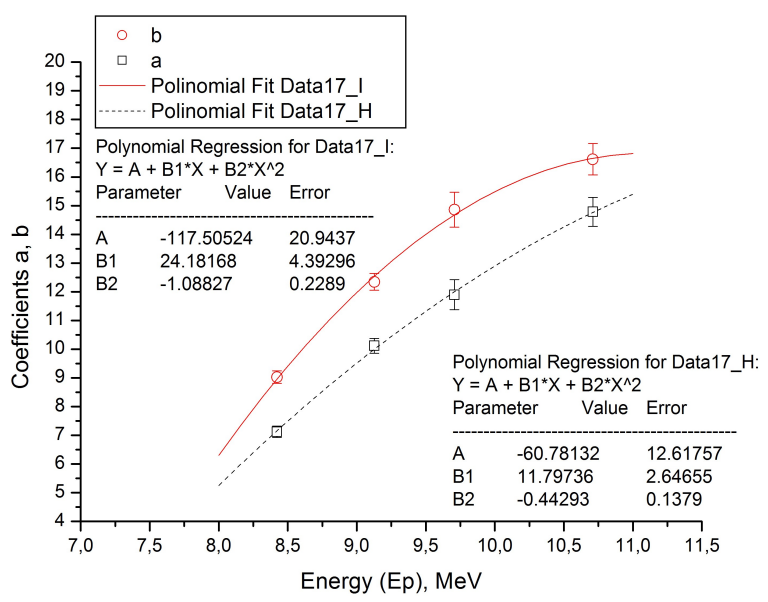

Figure 10. Dependence of the coefficients $a, b$ on most probable energy of electron beam

\section{CONCLUSIONS}

The implementation of the EPICS package unifies the control system of radiation processing and increases its reliability.

A method for continuous monitoring of critical parameters using a stack monitor located behind of irradiated object has been developed. The calibration procedures for measuring channels have been established and calibration coefficients have been obtained to control the electron energy and absorbed dose during product treatment at the LU-10 accelerator in the beam energy range 8-10 $\mathrm{MeV}$.

Continuous monitoring of the absorbed dose is important part of radiation technology, which enables the prompt adjustment of processing mode.

\section{REFERENCES}

1. D. Adlienè, R. Adlytè, "Dosimetry principles, dose measurements and radiation protection," in Applications of Ionizing Radiation in Materials Processing, vol. 1, Y. Sun, A. G. Chmielewski, Eds., Warszawa, Poland: INCT, 2017, ch. 3, p. 66. Retrieved from: http://www.ichtj.waw.pl/ichtj/publ/monogr/sun2017/ sun-chapter3.pdf Retrieved on: Jan. 10, 2019

2. R. I. Pomatsalyuk et al., "Development of a method of absorbed dose on-line monitoring at product processing by scanned electron beam," Probl. Atom. Sci. Technol., no. 3, pp. $149-153,2016$.

Retrieved from:

http://dspace.nbuv.gov.ua/bitstream/handle/1234567 89/115370/47-Pomatsalyuk.pdf?sequence $=1$

Retrieved on: Jan. 10, 2019

3. Experimental Physics and Industrial Control System (EPICS), Argonne National Laboratory, Lemont (IL), USA.

Retrieved from:

http://www.aps.anl.gov/epics/

Retrieved on: Jan. 10, 2019

4. R. I. Pomatsalyuk, V. L. Uvarov, V. A. Shevchenko, I. N. Shlyakov, "Modernization of Control System of the Beam Critical Parameters at a LU-10 Industrial Electron Accelerator," Probl. Atom. Sci. Technol., no. 6, pp. 175 - 180, 2017.

Retrieved from:

http://dspace.nbuv.gov.ua/bitstream/handle/1234567 89/136195/41-Pomatsalyuk.pdf?sequence $=1$

Retrieved on: Jan. 10, 2019

5. The EPICS Archiver Appliance, AccelUtils collaboration.

Retrieved from:

https://slacmshankar.github.io/epicsarchiver docs/in dex.html

Retrieved on: Jan. 10, 2019

6. R. I. Pomatsalyuk et al., "Measurement of Electron Beam Energy Characteristics at an Industrial Accelerator," Probl. Atom. Sci. Technol., no. 6, pp. 3-7, 2017.

Retrieved from:

http://dspace.nbuv.gov.ua/bitstream/handle/1234567 89/136210/01-Pomatsalyuk.pdf?sequence $=1$ Retrieved on: Jan. 10, 2019

7. Practice for dosimetry in an electron beam facility for radiation processing at energies between $300 \mathrm{keV}$ and $25 \mathrm{MeV}$, ISO/ASTM 51649:2015, Mar. 15, 2015.

8. Risø High Dose Reference Laboratory (Risø HDLR), Calorimeters, DTU Nutech Center for Nuclear Technologies, Copenhagen, Denmark. Retrieved from:

https://www.nutech.dtu.dk/english/Products-andServices/Industrial-Dosimetry/HDRL/calorimeters Retrieved on: May 20, 2021.

9. Practice for use of calorimetric dosimetry systems for dose measurements and dosimetry system calibration in electron beams, ISO/ASTM 51631:2020, Feb. 25, 2020. 